\title{
CLINICAL AND BACTERIOLOGICAL ASPECTS OF IMPETIGO CONTAGIOSA
}

\author{
BY GEORGE I. BARROW \\ From the Public Health Laboratory, Bradford
}

'Impetigo contagiosa' may be defined as an acute superficial infection of the skin, vesicular at the onset and crusted in development, which heals completely without scar formation, and leaves little or no immunity. Despite its familiarity, the exact nature of the causal organism has been disputed since the disease was first described by Tilbury Fox in 1864, and designated as a bacterial infection by Radcliffe Crocker in 1881. In the past it has frequently been attributed to haemolytic streptococci (see Percival, 1929; Cruickshank, 1941), and more recently to staphylococci (Bigger \& Hodgson, 1943, 1944; Sheehan \& Fergusson, 1943), although it has been suggested that each of these organisms may be causative (Epstein, 1940; Cruickshank, 1953). A specific 'impetigococcus' has been postulated on epidemiological grounds (Hope Simpson, 1941), and also the view that an unidentified agent-possibly a virus-may be concerned in association with staphylococci (Bigger \& Hodgson, 1943).

This paper reports the results of a further investigation into the clinical, epidemiological and bacteriological features of impetigo contagiosa, referred to as 'impetigo', with particular reference to the phage-typing of staphylococci and serological typing of haemolytic streptococci.

\section{Clinical material}

\section{MATERIAL AND METHODS}

It was originally intended to examine only early cases of impetigo presenting with intact vesicles; this, however, was abandoned, as only one such case was seen after several weeks. Accordingly, all uncomplicated cases were investigated irrespective of their duration. As most cases were in the crusted stage when first seen, the term 'lesion' is used for the various lesions of impetigo, unless otherwise stated.

During the period June 1953 to July 1954 I examined 125 out-patients at the Department of Dermatology, Bradford Royal Infirmary. Of these, 119 (69 male, 50 female) were considered true cases of impetigo. Their ages, together with those of three 'control' groups, are shown in Table 1.

As each patient attended, a full history was obtained, and the case classified according to extent as mild (42), moderate (52) or severe (12). Single swabs were taken before treatment from the nose, throat and one recent lesion-the crust being lifted gently with sterile forceps and a dry swab carefully rubbed over the base. In suitable patients, intact vesicles were cleansed with acetone and the vesicle fluid was aspirated into sterile capillary tubes; crusts were also obtained from some of these patients. 


\section{Control groups}

When it was found that one phage 'type' was largely predominant in impetigo, swabs were taken from three 'control' groups in order to ascertain if this 'type' was common locally, or was special to impetigo.

\section{Table 1. Ages of impetigo and control patients}

Age
group
2 and under
$3-5$
$6-10$
$11-20$
$21-30$
$31-40$
$41-50$
$51-60$
over 60

Total no. of cases

$\begin{array}{crrr}\text { Impetigo } & \text { SI } & \text { ON } & \text { HN } \\ 18 & 8 & 4 & 6 \\ 23 & 5 & - & 3 \\ 25 & 9 & 7 & 4 \\ 23 & 19 & 20 & 3 \\ 12 & 17 & 3 & 12 \\ 7 & 13 & 6 & 8 \\ 7 & 13 & 6 & 6 \\ 3 & 9 & 2 & 6 \\ 1 & 7 & 2 & 2 \\ 119 & 100 & 50 & 50\end{array}$

SI, staphylococcal infections other than impetigo.

ON, outside 'normals'.

HN, hospital 'normals'.

\section{Series SI: staphylococcal infections other than impetigo}

A total of 101 staphylococcal strains were obtained from 100 patients (55 male, 45 female), from boils (30), abscesses (36), osteomyelitis (7), septicaemia (1), and miscellaneous superficial skin infections (27). This series was started in December 1953, and completed in September 1954.

Series $O N$ : outside 'normals'

Staphylococci, representing thirty-two different phage patterns, were cultured from nose (23) and throat (10) swabs of 50 persons who had had no direct contact with hospitals for some considerable time, but were referred to hospital with various non-infected conditions.

\section{Series $H N$ : hospital 'normals'}

Staphylococci, representing thirty-one different phage patterns, were cultured from nose (29) and throat (4) swabs of 50 hospital patients and staff. The patients were from general medical and surgical wards, and had been in hospital for $2-3$ weeks or more.

In addition to comparison of the control staphylococci with those of impetigo, series $\mathrm{HN}$ and $\mathrm{ON}$ also provide a measure for comparison with series SI, and with the nasal carriage rate in the impetigo cases. Streptococcal carriers were not studied because of the small number of streptococci isolated from the impetigo cases. 


\section{Bacteriological methods}

All swabs were plated on $7 \%$ layered horse-blood agar, usually on the same day, and always within $24 \mathrm{hr}$. Plates were examined after aerobic incubation overnight at $37^{\circ} \mathrm{C}$. From impetigo lesions, staphylococci, or haemolytic streptococci, or both, were usually obtained in 'pure' culture; other organisms were uncommon. Single colonies of coagulase-positive staphylococci (slide technique-CadnessGraves, Williams, Harper \& Miles, 1943) were subcultured, and tested for penicillin sensitivity with discs containing $2 \cdot 5 \mathrm{i}$.u. of penicillin. Coagulase-negative staphylococci were discarded. Haemolytic streptococci were grouped by Lancefield's (1933) method and their penicillin sensitivity determined. Strains other than group A were discarded.

Staphylococci were phage-typed in batches at the Public Health Laboratory, Sheffield, by the method of Williams \& Rippon (1952). Phages, comprising the 'basic set' of Williams, Rippon \& Dowsett (1953) with the subsequent addition of phage 71 (group II), were used at routine test dilution (R.T.D.), and at 1000 times this concentration. Haemolytic streptococci were typed serologically at the Streptococcus Reference Laboratory, Colindale, by both the slide-agglutination (Griffith, 1934) and precipitin (Swift, Wilson \& Lancefield, 1943) methods (see Report, 1954).

\section{CLINICAL FEATURES}

No unusual clinical features were noticed in the present impetigo cases. The sites of infection were: face and/or neck, $89 \%$; arms and/or legs, $29 \%$; and body, $9 \%$. No clinical distinction was observed between those lesions yielding pure staphylococci and those yielding pure streptococci, although the presence of streptococci was suspected in some of the more severe or long-standing cases. In these patients, crusts were more difficult to remove, and were often surrounded by inflammatory zones, with, in a few instances, enlargement of the regional lymph nodes.

\section{BACTERIOLOGY}

Only the two bacterial species Staphylococcus aureus (coagulase-positive staphylococci) and Streptococcus pyogenes (Lancefield group A) were considered. Of the 119 impetigo cases studied, lesion swabs yielded neither organism in 13 instances $(10.9 \%) ; 8$ of these patients had clinically resolving lesions. Of the 106 bacteriologically positive lesions, Staph. aureus was obtained in pure culture from 86 $(81 \%)$ and Strep. pyogenes in pure culture from $6(5.6 \%)$; both Staph. aureus and Strep. pyogenes were isolated in 12 instances $(11.4 \%)$, while Staph. aureus, together with streptococci not of group A, C or G, were present in two cases. In all, therefore, Staph. aureus was recovered from $100(94 \cdot 4 \%)$ and Strep. pyogenes from 18 $(17 \%)$ impetigo lesions in the present cases (Table 2).

For convenience, the bacteriological findings are considered separately under (A) staphylococci, (B) haemolytic streptococci, and (C) mixed infections with Staph. aureus and Strep. pyogenes. Virus studies (D) are reported last. 


\section{A. Staphylococci}

Most phage-susceptible staphylococci fall into one or other of three broad groups; those lysed by phages of more than one group are regarded as 'unclassifiable', and those not susceptible to any phage are termed 'untypable'. For this paper it is proposed to assume that all staphylococci susceptible to phage 71, but not to other group II phages, at R.T.D. are identical ('type 71 '), since such strains have not been encountered frequently before (see also Parker, Tomlinson \& Williams, 1955). The remaining staphylococci in group II, lysed by one or more of the phages $3 \mathrm{~A}$, $3 \mathrm{~B}, 3 \mathrm{C}, 55$ and often also 71 , have been classed together as 'other patterns'.

Table 2. Distribution of staphylococci and haemolytic streptococci from 106 cases of impetigo

\begin{tabular}{|c|c|c|c|c|c|c|c|c|}
\hline \multirow[b]{2}{*}{ Source } & \multirow[b]{2}{*}{$\begin{array}{c}\text { Staph. aureus } \\
\text { only }\end{array}$} & \multicolumn{3}{|c|}{$\begin{array}{c}\text { Staph. aureus and } \\
\text { haemolytic streptococci } \\
\text { Group }\end{array}$} & \multicolumn{3}{|c|}{$\begin{array}{c}\text { Haemolytic } \\
\text { streptococei only } \\
\text { Group }\end{array}$} & \multirow[b]{2}{*}{ Total } \\
\hline & & A & $\mathrm{C}$ & $\begin{array}{l}\text { Not A, } \\
\text { C or G }\end{array}$ & A & $\mathrm{C}$ & $\begin{array}{l}\text { Not A, } \\
\text { C or G }\end{array}$ & \\
\hline Lesion & 86 & 12 & - & 2 & 6 & - & - & 106 \\
\hline Nose & 48 & 4 & - & 2 & 3 & - & - & 57 \\
\hline Throat & 14 & 1 & 1 & 4 & 6 & 1 & 4 & 31 \\
\hline
\end{tabular}

\section{(i) Phage 'type' in impetigo lesions}

Ninety-seven of 100 staphylococci isolated from impetigo lesions were typable, and 3 were untypable (Table 3 ). Of the typable strains 89 were members of group II, and 2 were not classifiable. As many as 63 of the group II strains were the same, 'type 71 ', being lysed only by this phage at R.T.D. The staphylococci comprising

Table 3. Results of phage-typing Staphylococcus aureus from 100 cases of impetigo

\begin{tabular}{lrrr}
$\quad$ Group & \multicolumn{3}{c}{ No. of strains from } \\
I & Lesion & Nose & Throat \\
II $\left\{\begin{array}{c}\text { "Type 71 } \\
\text { Other patterns }\end{array}\right.$ & 3 & 3 & 2 \\
III & 26 & 29 & 13 \\
Untypable & 3 & 18 & 4 \\
Unclassifiable & 3 & 2 & - \\
$\quad$ Total & 2 & 1 & - \\
& 100 & 54 & 20
\end{tabular}

'other patterns' in group II varied slightly in their phage susceptibility; all but 3 were lysed by phage 71 , amongst others, either at R.T.D. or at $1000 \times$ R.T.D. They included 17 strains, closely related to 'type 71 ', which were lysed by phage 71 , and also by other group II phages, at $1000 \times$ R.T.D., but not by any dilute phage. Parker et al. regard these as 'weak $7 \mathrm{l}$ ' strains, and classify them as a subdivision of 'type 71 '. On this basis 'type 71 ' would account for 80 of the 100 staphylococci 
from impetigo lesions. Six further strains, although not included within 'type 71', were lysed at R.T.D. either by phages $55 / 71$ or $3 \mathrm{C} / 55 / 71$.

It is perhaps noteworthy that in 2 of the 3 cases yielding untypable strains from lesions, staphylococci of 'type 71 ' in one instance, and 'weak 71 ' in the other, were obtained from the nasal swabs. Staph. aureus was not isolated from the nose or throat of the third patient.

'Type 71 ' Staph. aureus was thus involved in at least $80 \%$ of the staphylococcal cases of impetigo. Furthermore, the control groups indicate that this 'type' is apparently uncommon in other situations.

(ii) Phage 'types' in control groups

Since one 'type' of Staph. aureus occurred frequently in impetigo, search was made for its presence in other staphylococcal infections. Table 4 gives the source and phage group of Staph. aureus from staphylococcal infections other than impetigo

Table 4. Phage-typing results of Staphylococcus aureus from the various lesions in staphylococcal infections other than impetigo (SI)

\begin{tabular}{lccccc}
\multicolumn{1}{c}{ Group } & $\begin{array}{c}\text { Superficial } \\
\text { lesions }\end{array}$ & Boils & Abscesses & $\begin{array}{c}\text { Osteomyelitis } \\
\text { and } \\
\text { septicaemia }\end{array}$ & Total \\
I & 3 & 7 & 10 & 3 & 23 \\
II 'Type 71' & 1 & - & - & - & 1 \\
III & 8 & 8 & 10 & 5 & 31 \\
Untypable & 10 & 4 & 5 & - & 19 \\
Unclassifiable & - & 2 & -11 & - & 2 \\
$\quad$ Total & 5 & 9 & 11 & - & 25 \\
& 27 & 30 & 36 & 8 & 101
\end{tabular}

(series SI). There are considerably fewer strains of group II, and considerably more of groups I and III than in the impetigo series, although the proportion of unclassified staphylococci is perhaps higher than usual. In contrast to the cultures from impetigo, 'type 71' was obtained in only one instance; this was from the cutaneous lesion of a suspected, but unconfirmed, case of anthrax. Other patterns in group II included 9 'weak 71' strains, cultivated from hand infections (2), axillary boils (2), and from one case each of sycosis barbae, nasal pustule, breast abscess, perianal abscess, and osteomyelitis. No particular phage group was associated with any particular type of lesion.

The results of phage-typing nose and throat staphylococci from the hospital 'normal' (series HN) and outside 'normal' (series ON) control groups are summarized, and compared with those of series SI in Table 5. The distribution of staphylococci among the phage groups was similar in each of the control series. In no case was Staph. aureus of 'type 71 ' isolated, although 1 throat swab, and 3 nasal swabs in series ON yielded 'weak 71 ' strains. In comparison with their frequency in impetigo lesions, it is striking that 'type 71 ' was obtained only once out of a total of 164 control staphylococci. It seems that in Bradford, as elsewhere (see Parker etal., 1955), 'type $71^{\prime}$ Staph. aureus is significantly associated with impetigo. 
(iii) Relation of penicillin sensitivity to phage 'type'

The penicillin sensitivity of 90 strains of Staph. aureus from impetigo lesions was determined, and $64(71 \%)$ were found to be resistant. Although some of these patients had used penicillin locally, this incidence was unexpectedly high for

Table 5. Results of phage-typing Staphylococcus aureus from the control series

\begin{tabular}{crrrc}
\multicolumn{1}{c}{ Group } & SI & ON & HN & $\begin{array}{c}\text { of all } \\
\text { controls }\end{array}$ \\
I & 23 & 10 & 4 & 37 \\
II \{'Type 71' & 1 & - & - & 1 \\
III Other patterns & 31 & 8 & 9 & 48 \\
Untypable & 19 & 5 & 6 & 30 \\
Unclassifiable & 2 & 3 & 7 & 12 \\
Total & 25 & 6 & 5 & 36 \\
The & 101 & 32 & 31 & 164
\end{tabular}

SI, staphylococcal infections other than impetigo.

ON, outside 'normal' nose and throat staphylococci.

HN, hospital 'normal' nose and throat staphylococci.

Table 6. Relation of penicillin sensitivity to phage-typing results of Staphylococcus aureus from impetigo and control series

\begin{tabular}{|c|c|c|c|c|c|c|c|c|c|c|}
\hline & \multicolumn{8}{|c|}{ Control series } & \multirow{2}{*}{\multicolumn{2}{|c|}{$\begin{array}{l}\text { Total of all } \\
\text { controls }\end{array}$}} \\
\hline & \multicolumn{2}{|c|}{ lesions } & \multicolumn{2}{|c|}{$\mathrm{s}^{\mathrm{SI}}$} & \multicolumn{2}{|c|}{$\mathrm{ON}$} & \multicolumn{2}{|c|}{$\overbrace{}^{\mathbf{H N}}$} & & \\
\hline & $\mathrm{s}$ & $\mathbf{R}$ & s & $\mathrm{R}$ & $\mathrm{s}$ & $\mathbf{R}$ & S & $\mathbf{R}$ & S & $\mathbf{R}$ \\
\hline I & 2 & - & 14 & 9 & 9 & 1 & 2 & 2 & 25 & 12 \\
\hline II 'Type 71' & 11 & 44 & 1 & - & - & 一 & - & 一 & 1 & - \\
\hline 11 Other patterns & 9 & 16 & 16 & 15 & 7 & 1 & 5 & 4 & 28 & 20 \\
\hline III & 1 & 2 & 9 & 10 & 3 & 2 & 2 & 4 & 14 & 16 \\
\hline Untypable & 2 & 1 & 1 & 1 & 3 & - & 3 & 4 & 7 & 5 \\
\hline Unclassifiable & 1 & 1 & 14 & 11 & 6 & - & 2 & 3 & 22 & 14 \\
\hline Total & 26 & 64 & 55 & 46 & 28 & 4 & 14 & 17 & 97 & 67 \\
\hline$\%$ & 29 & 71 & 54 & 46 & $87 \cdot 5$ & $12 \cdot 5$ & 45 & 55 & 59 & 41 \\
\hline
\end{tabular}

$\mathrm{S}$, penicillin-sensitive; $\mathrm{R}$, penicillin-resistant.

SI, staphylococcal infections other than impetigo.

ON, outside 'normal' nose and throat staphylococci.

HN, hospital 'normal' nose and throat staphylococei.

sporadic 'non-hospital' cases. In a recent survey in general practice, Roodyn (1954) found that only $25 \%$ of the strains tested were resistant. Other studies suggest that fewer penicillin-resistant staphylococci occur in phage group II than in groups I and III, which together include many of the hospital strains (Barber \& Whitehead, 1949; Williams et al. 1953; Rountree, 1953). It was, therefore, of some interest to see if there was any correlation between the unusually high incidence of both 'type 71' and penicillin-resistant Staph. aureus in this investigation (Table 6). Of 55 'type 71 ' lesion strains, $44(80 \%)$ were penicillin-resistant. 
'Other patterns' included 16 'weak 71 ' strains, 10 of which were resistant. Thus an inclusive total of $54(76 \%)$ of these staphylococci were resistant to penicillin. In only two instances did staphylococci from the nose differ in sensitivity from those in the lesions. In both cases penicillin-sensitive Staph. aureus (type 55/71) was obtained from the lesions, and resistant strains (type 55) from the nose.

In the control groups, the proportions of Staph. aureus resistant to penicillin were much lower-55\% in series $\mathrm{HN}, 46 \%$ in series SI, and only $12.5 \%$ in series ON. In series SI, the single 'type 71 ' strain, and 4 of the 9 'weak 71 ' strains were penicillin-sensitive, as were the 4 'weak 71 ' staphylococci in series $\mathrm{ON}$.

It seems, therefore, that a high proportion of 'type 71 ' staphylococci are in fact resistant to penicillin, although fewer of the 'weak 71 ' strains are resistant.

\section{(iv) Nasal carriage of staphylococci}

Nose and throat swabs were taken from all impetigo cases, and from the 'normal' control groups. Since the throat swabs yielded relatively few staphylococci only those from the nasal swabs need be considered. Nasal carriage of Staph. aureus is common in healthy persons, and is of considerable epidemiological importance in outbreaks of food-poisoning and other infective conditions. It has recently been suggested as the source of infection in some pyogenic skin diseases, including impetigo (Hobbs, Carruthers \& Gough, 1947 ; Tulloch, 1954 ; Cruickshank, 1953).

Fifty-four of the 100 impetigo patients yielding staphylococci from lesions harboured Staph. aureus in the nose. In 8 of these 54 cases, the staphylococci cultivated from the nose were different from those in the lesions. Thus, based on single swabs, ony $46 \%$ of the impetigo patients carried the same strains of Staph. aureus in the nose and lesion. Considered separately, the incidence in 'type 71 ' cases was similar, $28(44 \%)$ of 63 patients carrying this strain in the nose. In general, the nasal carriage rate of staphylococci in the impetigo cases was similar to that of the 'normal' control groups-46\% in series $\mathrm{ON}$, and $58 \%$ in series $\mathrm{HN}$.

The nasal carriage rate of Staph. aureus in the impetigo patients $(46 \%)$ was, therefore, surprisingly low, especially since active, infective lesions were present on the face or neck in $89 \%$ of the cases. Moreover, although $44 \%$ of 'type 71 ' staphylococci is a considerable frequency of nasal carriage for one 'type', nevertheless, if the nose were the source of infection in impetigo, a greater measure of carriage might be expected.

\section{B. Haemolytic streptococci}

Six of 18 strains of Strep. pyogenes obtained from impetigo lesions were isolated in pure culture, and 12 in mixed culture with Staph. aureus. Of these 18 strains, 8 reacted in both precipitin and slide-agglutination tests, 8 only in the slideagglutination test, and 2 were not typable (Table 7). The penicillin sensitivity of 13 of the streptococci was determined, and all were sensitive.

Four of the 16 typable strains were each agglutinated by sera for the types 3 , 13 and B 3264; three of these were obtained from members of one family, and in two cases in pure culture. 
C. Mixed infections with Staphylococcus aureus and Streptococcus pyogenes

As mentioned previously, Staph. aureus and Strep. pyogenes were obtained in mixed culture from 12 patients. It will be seen from Table 7 that Staph. aureus of 'type 71 ' was not associated with Strep. pyogenes of agglutination pattern 3/13/B 3264 .

Table 7. Distribution of Streptococcus pyogenes serotypes from impetigo cases

Strep. pyogenes

\begin{tabular}{|c|c|c|c|c|c|c|c|c|c|c|}
\hline \multicolumn{5}{|c|}{ Strep. pyogenes } & \multirow{2}{*}{\multicolumn{4}{|c|}{ Staph. aureus }} & \multicolumn{2}{|c|}{ Impetigo } \\
\hline \multicolumn{2}{|c|}{ Serological type } & \multirow[b]{2}{*}{ Lesion } & \multirow[b]{2}{*}{ Nose } & \multirow[b]{2}{*}{ Throat } & & & & & Dura- & \\
\hline Precipitin & Agglutinin & & & & pattern & Lesion & Nose & Throat & $t$ (days) & Sever \\
\hline 1 & 1 & + & + & $-i$ & & & & & 5 & Mod. \\
\hline$\dagger-$ & 6 & + & - & -1 & & & & & 15 & Seve \\
\hline 28 & 28 & + & + & $\ldots$ & Strep. pyogenes in & pure cult & ture & & 7 & Mod. \\
\hline- & $5 / 27 / 44$ & + & - & $\ldots$ & & & & & 3 & Mild \\
\hline - & $3 / 13 /$ B 3264 & + & - & - & & & & & 4 & Mod. \\
\hline - & 3/13/B 3264 & + & -- & -1 & & & & & 4 & Mod. \\
\hline - & $3 / 13 / B 3264$ & + & + & - & $52 / 52 \mathrm{~A} / 79^{*}$ & + & + & - & 2 & Mild \\
\hline - & $8 / 25 / 10$ & + & - & + & $29 / 52$ & + & - & + & 17 & Mod. \\
\hline 1 & 1 & + & - & + & 71 & + & + & - & 13 & Mod. \\
\hline - & $8 / \operatorname{Imp} .19 / 10$ & + & + & + & 71 & + & + & - & 28 & Mod. \\
\hline - & $5 / 11 / 27 / 44$ & + & - & - & 71 & + & + & + & 14 & Mod. \\
\hline - & 4 & + & - & - & 71 & + & + & + & 4 & Seve] \\
\hline$l$ & 1 & + & + & + & 55 & + & - & - & 13 & Mod. \\
\hline 33 & $3 / 13 /$ B 3264 & + & - & $\ldots$ & $3 \mathrm{C} / 55 / 71^{*}$ & + & - & - & 28 & Mild \\
\hline 28 & 28 & + & + & + & $3 \mathrm{~A} / 3 \mathrm{~B} / 3 \mathrm{C} / 55 / 71^{*}$ & + & - & - & $14+$ & Mod. \\
\hline Untypal & & + & - & + & $79 / 3 \mathrm{C} / 55 / 71^{*}$ & + & + & - & $21+$ & Sever \\
\hline Untypab & & + & - & - & $3 \mathrm{C} / 55 / 71 / 53^{*}$ & + & - & - & 7 & Mild \\
\hline 6 & 6 & + & + & 一 & $79 / 55 / 71 / 53^{*}$ & + & - & - & 7 & IIild \\
\hline Total & - & 18 & 7 & 6 & - & 12 & 6 & 3 & - & - \\
\hline
\end{tabular}

F, same family.

* At $1000 \times$ R.T.D.

$\dagger$ Brother had impetigo of 7 days' duration-yielded pure Staph. aureus of 'type 71 '.

Although no clinical distinction was observed, 5 of the 6 'pure' streptococeal series were early cases of mild or moderate severity, with negative throat swabs. The remaining case was severe and of longer duration; his brother, seen at the same time, yielded a pure growth of 'type 71 ' staphylococci.

In general, the 12 cases with mixed infections were of greater severity and of longer duration than those of the 'pure' streptococcal series. Strep. pyogenes of the same type as those in the lesions was isolated from the nose and/or throat of 8 of these cases. In several instances the streptococci were probably secondary invaders, as their incidence increased with the age of the lesions, but the present numbers are too small to be significant. Conversely, in the mixed series, infection of the patient yielding Strep. pyogenes of agglutination pattern 3/13/B 3264 and Staph. aureus of phage-pattern 52/52 A/79 was probably primarily streptococcal, since this was an early case and a member of the same family as that in the 'pure' streptococcal series. 


\section{Virus studies}

Although Bigger \& Hodgson (1943) considered the possibility of a virus being associated with impetigo, attempts at virus isolation are not mentioned in the literature, as far as the author is aware.

Before this investigation commenced, the virus of herpes simplex was recovered, unexpectedly, from the fluid obtained from unruptured vesicles in two typical cases of impetigo. Since this virus is widely distributed, its association with impetigo, either causal or as a secondary invader, seemed possible. Accordingly, it was decided to look for this virus in a limited number of cases. Material from 10 cases was submitted to the Virus Reference Laboratory, Colindale, and from a further 10 cases to the University of Leeds. In no instance was this virus obtained.

It is concluded that the virus of herpes simplex is not related to impetigo, and that its role in the two cases cited was coincidental.

\section{EPIDEMIOLOGY}

The present impetigo series, apart from 13 family groups, comprised sporadic cases from different districts and social classes. Those affected were mostly children (Table 1), of whom 16 had previously suffered from impetigo. In 13 instances spread of impetigo occurred within families, accounting for 29 patients. In 11 of these family groups, staphylococci gave rise to impetigo in various members of the household over differing periods of time-from a few days to several weekssuggesting that the immediate infectivity of the organisms concerned was probably low. 'Type 71 ' Staph. aureus was involved alone in 7 of these families, embracing 14 patients. In one family 'weak 71 ' strains were isolated. Members of other 3 families yielded the following staphylococci: (1) 2 cases, 71 and untypable; (2) 3 cases, 55, 55/71 and 55/71; (3) 2 cases, 71 and 55/71.* In yet another family, Staph. aureus of 'type 71' was obtained from one member, and Strep. pyogenes of agglutination-type 6 from the other. The 'pure' streptococcal series included the only family in which all the members were affected more or less simultaneously.

Detailed histories were taken from each patient in an attempt to correlate the mode of spread with known impetigo contact, or with other possible sources of infection within the vicinity. It was soon evident, however, that the majority of cases remembered contact, in one way or another, with various septic conditions, and their significance is therefore doubtful.

On the other hand, a definite history of previous impetigo contact might prove of value if related to 'type 71 ' staphylococci. Of 39 patients who were known to have been in contact with impetigo, 31 yielded 'type 71 ', and 5 'weak 71 ' staphylococci from lesions. Staphylococei of 'type 71 ' were isolated from 32 , and 'weak 71 ' from 12 , of the 67 patients without such a history. Thus over $90 \%$ of those cases with known impetigo contact yielded Staph. aureus of 'type 71', compared with $65 \%$ in those without definite contact—suggesting that the mode of spread is by the transfer of organisms from case to case. 


\section{TREATMENT}

Many patients, when first seen, had tried a variety of local applications without effect, including 24 known to have used penicillin. After investigation each patient was instructed to apply ointment (aureomycin in 87 cases; neomycin in 32 ) to all lesions thrice daily after cleaning and decrusting, and to attend for review one week later. Eight extensive cases were treated in hospital.

The response to treatment was rapid, most patients stating that fresh lesions soon ceased to appear, and that healing had usually occurred within 3-5 days. At review, all except 7 cases were clear, apart from residual erythema and scaling indicating the site of previous lesions. Complications of impetigo, or of treatment, were not seen. No case has recurred, so far as is known. Similar results with aureomycin and neomycin locally were reported by Solomons (1951) and Church (1954).

\section{DISCUSSION}

The severity of impetigo contagiosa has diminished considerably since it was first described by Tilbury Fox in 1864. It was then apparently highly contagious, characterized by fever and general malaise, and liable to complications now recognized as streptococcal. At the present time it appears to be milder and less contagious. A recent increase in frequency has, however, been noted (Sneddon, 1953). Seasonal variations in incidence, as well as attempts at correlation with various streptococcal diseases, especially scarlet fever, have also been reported (Newman, 1935; Cruickshank, 1941), but the latter has yet to be established. Although sought, there was no association with other diseases in this study, nor was there any outstanding seasonal or sex distribution.

Impetigo has been classified clinically into staphylococcal and streptococcal types, though clinical differentiation in individual cases is not always possible (Lewandowsky, 1922; Epstein, 1940; Cruickshank, 1953). In the former, cases are often sporadic, and the lesions characterized by bullae, followed by thin crusts which may show central healing, with a clean base. The latter is apt to become 'epidemic', and is associated with thick 'stuck-on honey-coloured' scabs with inflammatory edges and a 'sodden' base (Lancet, 1943).

The present series consisted of sporadic cases occurring mostly in children, and it is notable that nearly all yielded staphylococci. The bacteriological findings, based on single swabs, indicate that Staph. aureus was cultivated altogether from $94 \%$ of the lesions, and Strep. pyogenes similarly from $17 \%$ of cases. Although Staph. aureus was isolated alone in $86(81 \%)$ instances, and Strep. pyogenes alone from $6(5 \cdot 6 \%)$ lesions, no clinical distinction was observed between these cases. Indeed, the finding of haemolytic streptococci in pure culture from early lesions was unexpected. Their presence was, however, suspected in some of the older lesions. It is possibly significant that the 'pure' streptococcal cases included the only 'epidemic' incident in which one entire family was affected almost simultaneously.

Similar bacteriological results were obtained from adult cases by both Sheehan \& Fergusson (1943) and Bigger \& Hodgson (1943), who considered that Staph. 
aureus was either the causative organism, or was of importance in the aetiology of impetigo, and that streptococci were seldom, if ever, the cause. In spite of the frequent occurrence of staphylococci, and infrequent finding of streptococci in impetigo, the available evidence suggests that either organism may be causative. In this respect it is interesting that, in a recent survey by the Public Health Laboratory Service of the relative prevalence of various streptococcal serotypes in this country, streptococei of the serological group 3/13/B 3264 were found to be significantly associated with impetigo and other skin sepsis (Report, 1954). In this investigation, Strep. pyogenes was isolated from only a small proportion of cases, but of the 16 typable strains obtained, 4 were members of this group, 3 of which were from the entire family already mentioned. The use of selective media might have yielded some additional streptococci, but probably not enough to affect the present results appreciably. It is suggested that sporadic impetigo is largely due to Staph. aureus, whereas increases in prevalence or severity are probably associated with a greater proportion of the streptococcal form.

Although most of the present cases were in the crusted stage when first seen, the fact that at least $80 \%$ of the staphylococci isolated from lesions were of the same, or closely related, phage ' type 71 ', suggests that their role was probably concerned with the initiation of infection, and that they were not merely 'opportunists'. They did not seem to represent a local strain of unusual virulence because they were rare in other lesions, and, indeed, the same 'type' has also been found widely distributed in impetigo cases in other parts of this country by Parker et al. (1955).

The mechanism of infection is still unknown, but it is generally agreed that some degree of trauma is essential for its initiation. Despite its frequency and accessible situation, experimental attempts to reproduce impetigo have largely failed; however, Sheehan \& Fergusson (1943) claimed some success using either Staph. aureus, or vesicle fluid. Other environmental or host factors, such as an alteration of immunity or in the metabolism of the skin itself, also may be involved.

As regards the organisms themselves, fluid from early, unruptured vesicles has variously yielded either Staph. aureus or Strep. pyogenes alone, or together in mixed culture (see Percival, 1929; Sheehan \& Fergusson, 1943; Bigger \& Hodgson, $1943,1944)$, and it has often been presumed that the organisms thus isolated were causative. It is doubtful if this view is fully justifiable, since the vesicles are formed primarily in the epidermis, not by haematogenous dissemination, but by the growth and multiplication of organisms at sites of supposed minor injury. Other organisms, not necessarily pathogenic, may therefore co-exist in vesicles $a b$ initio, and this may be illustrated by two of the present cases. Fluid from intact vesicles of 7 patients was examined bacteriologically: 5 yielded pure Staph. aureus, of which 4 were 'type 71 ' and one 'weak 71'. A mixed growth of Strep. pyogenes and 'weak 71 ' Staph. aureus was obtained from the two remaining cases-brothers seen at the same time. In both instances the streptococcal strains isolated were untypable, and it seems significant that a similar strain was obtained from the throat of the longer-standing case, with an antecedent history of sore throat.

Bigger \& Hodgson (1944), in an effort to trace the source of the infecting organisms, swabbed the nose, throat and skin near lesions of a small number of patients. From 
their results they surmised that, in at least some cases, the staphylococci were derived from the nose, and the streptococei from the throat. In the present cases, only $46 \%$ carried the same strain of Staph. aureus in the nose and lesion at the time of swabbing. Most of these patients were seen during the first or second week of disease. This figure is surprisingly low, since active lesions were present on the face or neck in $89 \%$ of cases. Valentine \& Hall-Smith (1952) recorded nasalcarriage rates of $68-80 \%$ in cases of furunculosis, and as high as $91 \%$ in sycosis barbae. If the nose were the source of infection in impetigo, it would presumably remain infected while the skin lesions were active, and a much higher incidence of nasal carriage would be expected. Further, if this were the case, some relapses might be expected, but despite the fact that no effort was made to suppress staphylococci in the nose, no case has so far recurred. Moreover, Strep. pyogenes was not found in the throat of any patient in the 'pure' streptococcal series. It is doubtful, therefore, if the nose or throat are the source of the causal organisms of impetigo, though they probably harbour some of the contaminants. It seems more likely, especially in children, that they are transferred by direct contact, and that the nose is secondarily infected. In some instances, primary contamination of the nose may occur, with subsequent infection of the skin, or of other persons. No doubt occasional carriers occurred amongst these cases, even though nasal carriage of 'type 71 ' staphylococci was not detected in the 'normal' control groups.

From this and other investigations, there seems to be good clinical, epidemiological and bacteriological evidence in favour of the existence of two forms of impetigo, caused by staphylococci and streptococci respectively; and in each form, particular 'types' of Staph. aureus and Strep. pyogenes appear to be largely concerned. In view of this, and the belief that vesicle fluid ought to yield pure cultures, it is hardly surprising that so much conflicting evidence and controversy have arisen in the past about the aetiology of the disease.

As early as 1906, Clegg \& Wherry suggested that the natural habitat and absence of invasiveness distinguished the impetigo organisms from the ordinary pyogenic cocci. More recently, Hope Simpson (1941) has indicated that impetigo is a distinct infection which breeds true; that contacts of impetigo do not develop other pyogenic lesions, and, conversely, that contact with boils and other septic conditions does not give rise to impetigo. He postulated on these grounds that, whatever its precise nature, 'the causal organism of impetigo contagiosa is an organism special to that disease', for which he suggested the title 'impetigococcus'.

It is of considerable interest that so many impetigo staphylococci should be lysed by one unusual phage, since the correlation of a particular 'type' with a constant pathological lesion has rarely been found. This 'type' seems to be characterized not only by its susceptibility to phage 71 , but also to a great extent by its resistance to penicillin. It seems to have little or no invasive power, its activity being limited to the superficial layers of the skin, where it provokes only a mild pyogenic response. Staphylococci of 'type 71 ', at least-and possibly also some streptococci-thus appear to fulfil the criteria of Hope Simpson's specific 'impetigococcus'. 


\section{SUMMARY}

1. The results of an investigation into the clinical, epidemiological and bacteriological features of impetigo contagiosa, with special reference to the type identification of staphylococci and streptococci, are reported and discussed.

2. Of 106 impetigo cases studied, Staphylococcus aureus was isolated alone from 86 lesions (81\%), Streptococcus pyogenes alone from $6(5 \cdot 6 \%)$, and a mixed growth of Staph. aureus and haemolytic streptococci in 14 instances $(13.2 \%)$.

3. Of the 100 strains of Staph. aureus isolated from impetigo lesions, 63 were identical in phage type ('type 71 '), and a further 17 were closely related ('weak 71 ').

4. Only one representative of 'type 71', and 9 of 'weak 71 ', were obtained from 164 strains of Staph. aureus from 200 persons in three control groups.

5. Of 90 strains of Staph. aureus from impetigo lesions, $64(71 \%)$ were resistant to penicillin. Of these penicillin-resistant strains, $54(84 \%)$ were of 'type 71 ', or close variants.

6. Strep. pyogenes was probably causative in at least 6 of the 18 patients yielding this organism from lesions; it was presumed to be a secondary invader in the remainder.

7. It is doubtful if nasal carriage is of importance in the epidemiology of impetigo.

8. It is concluded that there is a specific 'type' of staphylococcus associated with this form of impetigo.

I am grateful to Dr H. G. Smith of the Public Health Laboratory, Bradford, for his interest, advice, and for assistance with the bacteriology, and to Dr Allan Bigham, in whose department the clinical work was done, for his encouragement. I wish to thank Dr E. H. Gillespie, of the Public Health Laboratory, Sheffield, and Dr R. E. O. Williams, of the Streptococcus Reference Laboratory, Colindale, for typing staphylococci and streptococci respectively, and for their helpful criticism. I am indebted to Dr F. O. MacCallum, of the Virus Reference Laboratory, Colindale, and Dr T. H. Flewett, of the Department of Bacteriology, University of Leeds, for their virus work. My thanks are also due to the general practitioners who kindly referred cases to me, and to the staff of the Department of Dermatology, Bradford Royal Infirmary for their co-operation.

\section{REFERENCES}

Barber, M. \& Whitemead, J. E. M. (1919). Bacteriophage types in penicillin-resistant staphylococcal infection. Brit. med. J. ii, 565 .

Bigger, J. W. \& Hodgson, G. A. (1943). Impetigo contagiosa; its cause and treatment. Lancet, i, 544.

BIGGER, J. W. \& Hodgson, G. A. (1944). Impetigo contagiosa treated with microcrystalline sulphathiazole. Lancet, ii, 78.

Cadness-Graves, B., Williams, R., Harper, G. J. \& Miles, A. A. (1943). Slide-test for coagulase-positive staphylococci. Lancet, i, 736 .

Church, R. (1954). Neomycin in pyogenic skin diseases. Brit. med. J. i, 314.

Clegg, M. T. \& Wherry, W. (1906). The etiology of pemphigus contagiosus in the tropics. J. infect. Dis. 3, 165. 
Crocker, H. R. (1881). On the contagion of impetigo contagiosa. Lancet, i, 821.

Cruickshank, R. (1941). Bacteriology of impetigo contagiosa. Lancet, ii. 275.

Cruickshank, R. (1953). The epidemiology of some skin infections. Brit. med. J. i, 56.

Epstein, S. (1940). Staphylococcic Impetigo contagiosa. Arch. Derm. Syph., Chicago, 20, 187.

Fox, W. T. (1864). On impetigo contagiosa or porrigo. Brit. med. J. i, 467.

GrIfFiтh, F. (1934). The serological classification of Streptococcus pyogenes. J. Hyg., Camb., 34,542 .

Hobbs, B. C., Carruthers, H. L. \& Govgh, J. (1947). Sycosis barbae; serological types of Staphylococcus pyogenes in nose and skin, and results of penicillin treatment. Lancet, ii, 572.

Hope Simpson, R. E. (1941). The impetigococcus. Lancet, i, 683.

LANCEFIELD, R. C. (1933). A serological differentiation of human and other groups of haemolytic streptococci. J.exp. Med. 57, 571.

Lancet (1943). (Leading Article), i, 559.

Lewandowsky, F. (1922). Zur Impetigofrage. Arch. Derm. Syph., Wien, 138, 438.

Newman, J. L. (1935). Impetigo contagiosa, its epidemiology and control. J. Hyg., Camb., 35, 150.

Parker, M. T., Tomlinson, A. J. H. \& Williams, R. E. O. (1955). Impetigo contagiosa: the association of certain types of Staphylococcus aureus and of Streptococcus pyogenes with superficial skin infections. J. Hyg., Camb., 53, 458.

Percival, G. H. (1929). System of Bacteriology, 2, 75 et seq. London: Med. Res. Council.

REPORT (1954). Serotypes of Streptococcus pyogenes. Their relative prevalence in England, Wales and Northern Ireland, 1952-53. Mon. Bull. Minist. Hlth Lab. Serv. 13, 171.

Roodyn, L. (1954). Staphylococcal infections in general practice. Brit. med. J. ii, 1322.

Rountree, P. M. (1953). Bacteriophage typing of strains of staphylococci isolated in Australia. Lancet, i, $\mathbf{5 1 4}$.

Sheehan, H. L. \& Fergusson, A. G. (1943). Impetigo: aetiology and treatment. Lancet, i, 547.

Sneddon, I. B. (1953). Skin affections of the school-child. Publ. Hlth, 67, 5.

Solomons, B. (1951). Aureomycin, its topical use in some skin diseases (A clinical study). Brit. med. J. ii, 525 .

Swift, H. F., Wrlson, A. T., \& Lancerteld, R. C. (1943). Typing Group A haemolytic streptococei by $M$ precipitin reactions in capillary pipettes. J. exp. Med. 78, 127.

Tulloch, L. G. (1954). Nasal carriage in staphylococcal skin infections. Brit. med. J. ii, 912.

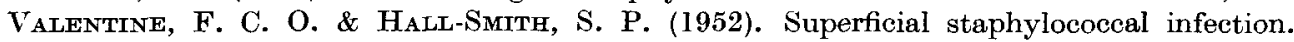
Lancet, ii, 351.

Williams, R. E. O. \& Rippon, J. E. (1952). Bacteriophage typing of Staphylococcus aureus. J. Hyg., Camb., 50, 320.

Wrultams, R. E. O., Rippon, J. E. \& Dowsett, L. M. (1953). Bacteriophage typing of strains of Staphylococcus aureus from various sources. Lancet, i, 510. 